\title{
Correction to: pygrametl: A Powerful Programming Framework for Easy Creation and Testing of ETL Flows
}

\author{
Søren Kejser Jensen (D), Christian Thomsen (D), \\ Torben Bach Pedersen (D), and Ove Andersen (D)
}

Correction to:

Chapter "pygrametl: A Powerful Programming Framework for Easy Creation and Testing of ETL Flows" in:

A. Hameurlain and A Min Tjoa (Eds.):

Transactions on Large-Scale Data- and Knowledge-Centered Systems XLVIII, LNCS 12670,

https://doi.org/10.1007/978-3-662-63519-3_3

In the originally published version of chapter 3, there was an error in the affiliation and email address of the author Ove Andersen, as well as in reference 17. This has been corrected. 